\title{
Novel Influences of Sex and APOE Genotype on Spinal Plasticity and Recovery of Function after Spinal Cord Injury
}

\author{
Lydia E. Strattan, ${ }^{1}$ Daimen R. S. Britsch, ${ }^{2}$ Chris M. Calulot, ${ }^{2}$ Rachel S. J. Maggard, ${ }^{1}$ Erin L. Abner, ${ }^{3,4,5}$ \\ Lance A. Johnson, ${ }^{3,6}$ and Warren J. Alilain ${ }^{1,2}$
}

https://doi.org/10.1523/ENEURO.0464-20.2021

${ }^{1}$ Department of Neuroscience, University of Kentucky College of Medicine, Lexington, KY 40536, ${ }^{2}$ Spinal Cord and Brain Injury Research Center, University of Kentucky College of Medicine, Lexington, KY 40536, ${ }^{3}$ Sanders-Brown Center on Aging, University of Kentucky, Lexington, KY 40504, ${ }^{4}$ Department of Biostatistics, University of Kentucky, Lexington, KY 40536, ${ }^{5}$ Department of Epidemiology, University of Kentucky, Lexington, KY 40536, and ${ }^{6}$ Department of Physiology, University of Kentucky College of Medicine, Lexington, KY 40536

\begin{abstract}
Spinal cord injuries can abolish both motor and sensory function throughout the body. Spontaneous recovery after injury is limited and can vary substantially between individuals. Despite an abundance of therapeutic approaches that have shown promise in preclinical models, there is currently a lack of effective treatment strategies that have been translated to restore function after spinal cord injury (SCl) in the human population. We hypothesized that sex and genetic background of injured individuals could impact how they respond to treatment strategies, presenting a barrier to translating therapies that are not tailored to the individual. One gene of particular interest is $A P O E$, which has been extensively studied in the brain because of its allele-specific influences on synaptic plasticity, metabolism, inflammation, and neurodegeneration. Despite its prominence as a therapeutic target in brain injury and disease, little is known about how it influences neural plasticity and repair processes in the spinal cord. Using humanized mice, we examined how the $\varepsilon 3$ and $\varepsilon 4$ alleles of $A P O E$ influence the efficacy of therapeutic intermittent hypoxia $(\mathrm{IH})$ in inducing spinally-mediated plasticity after cervical $\mathrm{SCl}(\mathrm{cSCl})$. IH is sufficient to enhance plasticity and restore motor function after experimental SCl in genetically similar rodent populations, but its effect in human subjects is more variable (Golder and Mitchell, 2005; Hayes et al., 2014). Our results demonstrate that both sex and APOE genotype determine the extent of respiratory motor plasticity that is elicited by $\mathrm{IH}$, highlighting the importance of considering these clinically relevant variables when translating therapeutic approaches for the $\mathrm{SCl}$ community.
\end{abstract}

Key words: apolipoprotein E; breathing; genetics; plasticity; spinal cord injury

\section{Significance Statement}

There is currently a critical need for therapeutics that restore motor and sensory function effectively after cervical spinal cord injury (cSCl). Although many therapeutic approaches, including intermittent hypoxia (IH), are being investigated for their potential to enhance spinal plasticity and improve motor outcomes after SCl, it is unknown whether the efficacy of these treatment strategies is influenced by individuals' genetic background. Here, we show that $A P O E$ genotype and sex both play a role in determining the propensity for motor plasticity in humanized mice after cervical SCI (cSCl). These results indicate that sex and genetic background dictate how individuals respond to therapeutic approaches, thereby emphasizing the importance of developing personalized medicine for the diverse SCI population. 


\section{Introduction}

Over 17,000 Americans experience a spinal cord injury (SCl) every year (National Spinal Cord Injury Statistical Center, 2018). Depending on the level of injury, damage to neural pathways in the spinal cord can lead to a multitude of sensory deficits and loss of crucial motor functions. Over the past few decades, many promising therapeutic approaches have been developed to enhance neuroprotection or induce anatomic and functional plasticity of spinal pathways to restore function (Fuller et al., 2003; Huie et al., 2017; Satkunendrarajah et al., 2018; Zholudeva et al., 2018; Jack et al., 2020). Moreover, pivotal studies using nerve grafts, PTEN deletion, NOGO inhibition, or degradation of the perineuronal net or chondroitin sulfate proteoglycans (CSPGs) have demonstrated that the CNS is capable of overcoming neural intrinsic and extrinsic barriers to regeneration after injury, leading to meaningful preclinical recovery (David and Aguayo, 1981; Chen et al., 2000; Park et al., 2008; Alilain et al., 2011; Urban et al., 2019). However, these therapeutic strategies have met with varied clinical success and there remains a lack of effective treatment strategies for the human SCl population (for review, see Ahuja et al., 2017).

A striking difference between individuals living with $\mathrm{SCl}$ and the animals used to model them is the level of genetic diversity represented in these populations. In contrast to the incredible diversity of the human population, preclinical studies typically use homogenous groups of animals with the same sex and similar genetic backgrounds. While this does facilitate easier determination of treatment effects, it also makes it less likely that discoveries in these models will translate to human patients. Although an increasing number of preclinical investigations are addressing how sex influences the efficacy of therapeutic strategies, the impact of genetic variability remains largely unexplored. A recent review by Fouad et al. (2020), specifically outlined the importance of

Received October 28, 2020; accepted January 22, 2021; First published February 3, 2021.

The authors declare no competing financial interests.

Author contributions: L.E.S., C.M.C., E.L.A., L.A.J., and W.J.A. designed research; L.E.S., D.R.B., C.M.C., and R.S.J.M. performed research; L.A.J. contributed unpublished reagents/analytic tools; L.E.S., E.L.A., and W.J.A. analyzed data; L.E.S., E.L.A., and W.J.A. wrote the paper.

This work was supported by the National Science Foundation Graduate Research Fellowship Grant 1839289. Any opinions, findings, and conclusions or recommendations expressed in this material are those of the authors and do not necessarily reflect the views of the National Science Foundation. This work was also supported by the Craig H. Neilsen Foundation Grant 598741 and by the National Institutes of Health Grant R01 (NS101105).

Acknowledgements: We thank Kyle Ritter, BS, Emily Huffman, BS, Jessica Newton, MS, and Laura Mendenhall for their assistance in completing experiments. We also thank Matt Hazzard at the University of Kentucky College of Medicine for designing circuitry illustrations.

Correspondence should be addressed to Warren J. Alilain at warren. alilain@uky.edu.

https://doi.org/10.1523/ENEURO.0464-20.2021

Copyright @ 2021 Strattan et al.

This is an open-access article distributed under the terms of the Creative Commons Attribution 4.0 International license, which permits unrestricted use, distribution and reproduction in any medium provided that the original work is properly attributed. evaluating the influence of factors such as sex and genotype to address the neuroanatomical-functional paradox and lack of therapeutic translation in SCl. Indeed, we hypothesize that genetic factors could play a considerable role in determining how individuals respond to treatment strategies.

Apolipoprotein E (ApoE) is a highly expressed lipid carrier in the CNS (Boyles et al., 1985). It is encoded by the $A P O E$ gene, which exists in three common alleles designated $\varepsilon 2, \varepsilon 3$, and $\varepsilon 4$. The $\varepsilon 4$ allele, which is carried by nearly one in five individuals, has been associated with a number of detrimental outcomes, including a weakening of synaptic plasticity in the brain (Zhao et al., 2018). However, despite a robust body of literature in neurodegenerative diseases and traumatic brain injury (Zhou et al., 2008; Mahley, 2016; Main et al., 2018); the impact of $\varepsilon 4$ on plasticity in the spinal cord remains underexplored. We hypothesized that spinally-mediated plasticity is constrained in apoE4 animals, thereby demonstrating the importance of considering the diversity of the human population when developing therapeutic approaches for people with SCl.

To test this hypothesis, we use a model of cervical injury to examine how $A P O E$ genotype alters the response to intermittent hypoxia $(\mathrm{IH})$. Most SCls occur at these high levels and can disrupt the neural circuitry that mediates breathing, leading to respiratory insufficiency and potentiating the need for mechanical ventilation (Bergofsky, 1964; Alp and Voss, 2006; National Spinal Cord Injury Statistical Center, 2018). Mechanical ventilation increases the risk of respiratory infection, a leading cause of rehospitalization and death following cervical $\mathrm{SCl}$ (cSCl; DeVivo and Ivie, 1995).

In recent years, there has been a growing appreciation for the potential of $\mathrm{IH}$ as a treatment strategy for a host of conditions including SCl (Navarrete-Opazo and Mitchell, 2014). In clinical trials, therapeutic IH has been used to increase limb function and to facilitate ventilation in persons with $\mathrm{SCl}$ by enhancing plasticity in the spinal cord (Tester et al., 2014; Lynch et al., 2017; Trumbower et al., 2017). Neural pathways in the cervical region which mediate breathing are critical therapeutic targets of $\mathrm{IH}$, including spared pathways which might remain after injury. However, the influence of human genetic variability on $\mathrm{IH}$-induced recovery is unknown. Therefore, we used this model of spinally-mediated plasticity to examine how expression of different human $A P O E$ alleles alter the efficacy of therapeutic strategies, such as $\mathrm{IH}$, that are being developed to enhance plasticity following $\mathrm{SCl}$. Our results provide evidence that both sex and $A P O E$ genotype determine the propensity for plasticity in humanized mice that are exposed to therapeutic $\mathrm{IH}$.

\section{Materials and Methods}

\section{C2 hemisections}

All experiments were approved by the Institutional Animal Care and Use Committee at the University of Kentucky. Mice expressing human APOE isoforms under control of the mouse APOE promotor (targeted 
replacement mice) were backcrossed for at least 10 generations to the C57BL/6 background (Sullivan et al., 1997, 1998; Knouff et al., 1999). Mice were group-housed on a $12 / 12 \mathrm{~h}$ light/dark cycle and fed normal chow diet ad libitum. All mice were $92-105 \mathrm{~d}$ old at the time of injury. Female (20-24 g) and male (22-30 g) mice were anesthetized with isoflurane. Animals were then prepped for surgery by shaving the surgical area followed by disinfecting with alternating betadine and $70 \%$ ethanol swabs. Puralube ophthalmic ointment was applied to the eyes to prevent drying during surgery. A midline incision was made through the skin just caudal to the ears to between the scapulae. Marcaine/bupivacaine was instilled along the incision site. The acromiotrapezius, semispinalis capitus, and rectus capitus posterior muscles were cut along their midline, bluntly dissected, and retracted. Paravertebral muscles were cut away from the C2 vertebra using ToughCut Spring Scissors (Fine Science Tools). The lamina of the C2 vertebra was then removed using Spring Scissors. Under a dissecting microscope (Meiji EMZ), a left lateral $\mathrm{C} 2$ hemisection $(\mathrm{C} 2 \mathrm{Hx})$ was performed by inserting a 27-gauge needle into the midline of the spinal cord at the C2 level and dragging the needle to the left lateral edge of the cord. This was then repeated once to ensure a complete injury. Musculature was sutured (6-0 absorbable suture) and skin was closed with Vetbond Tissue Adhesive (3 M). Animals received subcutaneous buprenorphine $(0.75 \mathrm{mg} / \mathrm{kg})$ and carprofen $(10 \mathrm{mg} / \mathrm{kg})$ immediately after surgery. Male mice were housed individually following surgery to prevent fighting among cage mates.

\section{IH and diaphragmatic electromyography (EMG)}

Three weeks after hemisection, animals were anesthetized with isoflurane using the SomnoSuite Anesthesia System (Kent Scientific). A laparotomy was performed by cutting through the rectus abdominis, external oblique, and internal oblique muscles. Bipolar electrodes, connected to an amplifier and data acquisition system (CWE BMA-400 Four-channel Bioamplifier, CED 1401 with Spike2 Data Analysis Computer Interface), were inserted into the dorsal region of the left hemidiaphragm, where they were secured using Vetbond. Bilateral recordings were not performed because of the increased attrition rate we observed after performing bilateral electrode insertion. The laparotomy was also closed using Vetbond; $10 \mathrm{~min}$ of baseline breathing activity was recorded. The air input to the Somnosuite was then changed from room air (normoxia) to a tank of $11 \%$ oxygen, $89 \%$ nitrogen gas (hypoxia) for $5 \mathrm{~min}$, at which point it was switched back to room air for $5 \mathrm{~min}$. This was repeated for three bouts of hypoxia separated by $5 \mathrm{~min}$ of normoxia. Diaphragmatic activity was recorded for $1 \mathrm{~h}$ after the final hypoxic bout (Fig. 1A). Although core temperature was not monitored during recordings, animals were kept on heating pads throughout all recording procedures to maintain body temperature.

\section{Sectioning and staining}

To harvest tissue for immunohistochemistry, mice were perfused with $4 \%$ paraformaldehyde (PFA) following the diaphragmatic EMG recording. The spinal column was isolated and placed in $4 \%$ PFA at $4^{\circ} \mathrm{C}$. After $2 \mathrm{~d}$, tissue was removed from PFA and placed in a $30 \%$ sucrose solution at $4^{\circ} \mathrm{C}$ for cryoprotection until sectioning.

Tissue was mounted and frozen in Tissue Plus O.C.T. Compount (Fisher Healthcare) and cut at a thickness of $20 \mu \mathrm{m}$ on a cryostat (Leica). Serial sections from the injury site $(\mathrm{C} 1-\mathrm{C} 2)$ were placed on one set of slides while serial sections from the level of the PMN (C3-C6) were placed on another set. Injured tissue slides were dehydrated in ethanol and stained with $0.1 \%$ cresyl violet solution (Sigma catalog \#C5042). Slides were then mounted using permount (Electron Microscopy Sciences catalog \#17986-01). For 5HT staining, frozen sections were thawed to room temperature, rinsed with $1 \times$ PBS, and blocked in a solution of $5 \%$ normal goat serum (NGS), $0.1 \%$ bovine serum albumin, and $0.1 \%$ Triton $\mathrm{X}-100$ dissolved in PBS. Slides were incubated in 5-HT primary antibody diluted 1:10,000 (rabbit, ImmunoStar catalog \#20080) then goat anti-rabbit Alexa Fluor 488 secondary antibody (1:500, Life Technologies catalog \#A11034). Stained slides were mounted with ProLong Gold mountant with DAPI (Invitrogen catalog \#P36931). For Wisteria floribunda lectin (WFA) staining, frozen sections were thawed to room temperature, washed with $1 \times$ PBS, then blocked in 3\% NGS diluted in PBS. Slides were then incubated in WFA primary antibody conjugated to Fluorescein at a dilution of 1:400 (Vector Labs catalog \#FL-1351). Stained slides were mounted in ProLong Gold with DAPI.

\section{Trace analysis}

After recording, raw diaphragmatic EMG was rectified and integrated using Spike2 software. Analysis was performed at twelve time points: twice during baseline recording, once during each hypoxic and normoxic bout, and at 10, 20, 30, and $40 \mathrm{~min}$ after the final hypoxic period (Fig. 1A). For each time point, peak amplitude was averaged over a $30-\mathrm{s}$ period. Amplitude of diaphragmatic bursts at each time point were normalized to that animal's prehypoxia baseline amplitude. Frequency of diaphragmatic bursts, indicative of breaths, was also quantified over a 30 -s period at each time point.

\section{Imaging and image quantification}

Staining for cresyl violet and WFA was imaged on a Keyence BZ-X810 fluorescence microscope for quantification. Cresyl violet-stained sections were imaged using brightfield illumination at $2 \times$. Sections stained for WFA were imaged at $10 \times$ using the monochromatic camera with high resolution $(0.75488 \mu \mathrm{m} /$ pixel) for quantification. Additional images for publication were acquired on a Nikon Eclipse Ti series inverted confocal at $40 \times$, focused on the ventral horn in the region of the putative PMN. Sections stained for 5-HT were imaged on the Nikon at $20 \times$. Images of $5-\mathrm{HT}$ staining for publication were taken at $40 \times$ in the region of the PMN. All imaging and quantification were performed on the ventral horn of the left side of the cord, ipsilateral to the injury. 
A

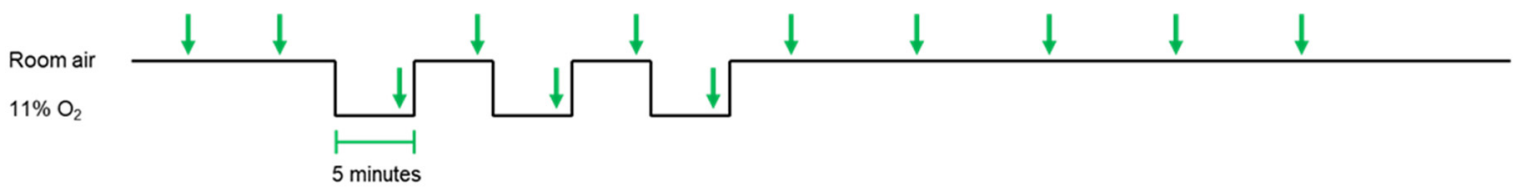

B

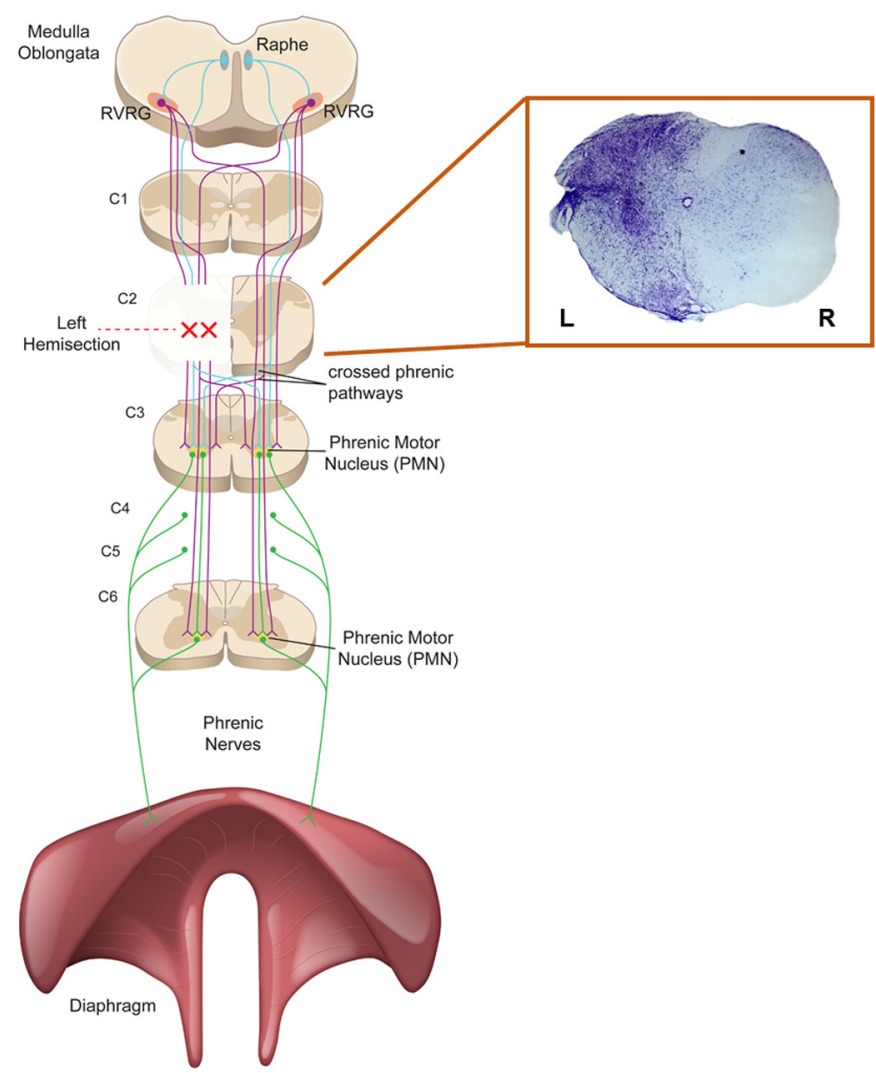

D

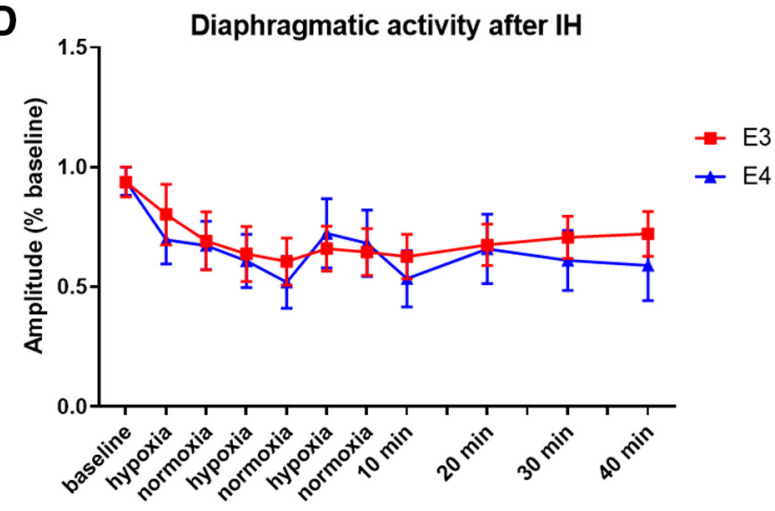

E

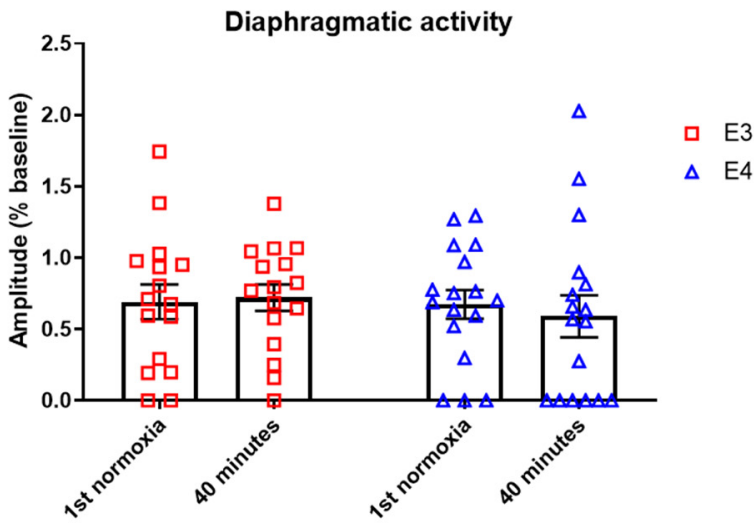

Figure 1. Magnitude of respiratory motor plasticity is not determined by APOE genotype alone. $\boldsymbol{A}$, Timeline of IH protocol. Green arrows represent time points at which peak amplitude was analyzed. $\boldsymbol{B}$, Schematic of the neural circuitry that mediates breathing. Location of the left C2 hemisection is indicated by red X. $\boldsymbol{C}$, Representative image of cresyl violet staining of the spinal cord at the C2 level after injury. $\boldsymbol{D}$, Quantification of diaphragmatic amplitude over time during and after IH. There was no difference between genotypes in the change in amplitude over time (a. RMANOVA $p=0.741, \mathrm{MD}=0.043, \mathrm{Cl}=-0.22-0.31$ ) $\boldsymbol{E}$, Quantification of diaphragmatic amplitude during the first normoxic bout and $40 \mathrm{~min}$ after $\mathrm{IH}$ (b. paired $t$ test E3 normoxia $\mathrm{V}$. $40 \mathrm{~min} p=0.741$, $\mathrm{MD}=0.029, \mathrm{Cl}=-0.16-0.22 ; \mathrm{c}$. E4 normoxia v. $40 \mathrm{~min} p=0.405, \mathrm{MD}=0.084, \mathrm{Cl}=-0.29-0.12)$. Bars show mean and $\mathrm{SEM}$ values.

WFA labeling was quantified using the HALO image analysis platform (Indica Labs). We developed and optimized an algorithm on the Area Quantification v1.0 to capture positive staining for WFA while omitting any nonspecific fluorescence. A region of interest (ROI) was drawn around the left ventral horn of sections at the level of $\mathrm{C} 4$. The quantification algorithm was applied to the ROI of each section. The area of staining was then normalized to the total area of the ROI. Three tissue sections at level C4 were analyzed for each animal. 5-HT labeling was also quantified with HALO. A ROI was drawn around the left ventral horn. Serotonergic fibers within the ROI were traced using the embedded annotation tool. The total length of fibers was then normalized to the area of the ROA.

\section{Experimental design and statistical analyses}

Sample sizes for mice receiving diaphragmatic EMG recordings were calculated based on preliminary data from 10 hemisected mice representing all three genotypes using Cohen's $d$ to measure effect size. Group sizes for each sex and genotype are found in Table 1. Tissue from a subset of animals was perfused with PFA and spinal cord tissue was harvested from these animals for IHC and

Table 1: Group sizes for diaphragmatic EMGs

\begin{tabular}{lll}
\hline & Male & Female \\
\hline E3 & $n=7$ & $n=8$ \\
E4 & $n=6$ & $n=11$
\end{tabular}


Table 2: Statistical tests

\begin{tabular}{lll}
\hline Data structure & Type of test & $95 \% \mathrm{Cl}$ \\
\hline a. Repeated measurements, normal distribution & RMANOVA & -0.2202 to 0.3063 \\
b. Normal distribution with within-subject correlation & Paired $t$ test & -0.1570 to 0.2160 \\
c. Normal distribution with within-subject correlation & Paired test & -0.2907 to 0.1235 \\
d. Repeated measurements, normal distribution & RMANOVA & -0.2958 to 0.35575 \\
e. Repeated measurements, normal distribution & RMANOVA & -1.17798 to 0.07798 \\
f. Repeated measurements, normal distribution & RMANOVA & -1.53798 to -0.2820 \\
g. Repeated measurements, normal distribution & RMANOVA & -0.9958 to -0.3442 \\
h. Repeated measurements, normal distribution & RMANOVA & -0.75238 to 0.11238 \\
i. Repeated measurements, normal distribution & RMANOVA & 0.426832 to 1.25317 \\
j. Repeated measurements, normal distribution & RMANOVA & 1.66683 to 2.49317 \\
k. Repeated measurements, normal distribution & RMANOVA & 0.64132 to 1.37868 \\
I. Normal distribution, Unequal variance & Welch's $t$ test & -0.0003607 to 0.006133 \\
m. Normal distribution & Student's $t$ test & 0.0003556 to 0.002912 \\
n. Normal distribution & Student's $t$ test & -0.001091 to 0.003178 \\
o. Normal distribution & Student's $t$ test & -0.2916 to 1.237
\end{tabular}

quantification of WFA and serotonergic sprouting (apoE3 $n=4$, apoE4 $n=5$ ).

For statistical analysis of EMG traces, repeated measures (RM)ANOVA was used to account for within-subject correlation given repeated measurements over time. Stratified RMANOVA analyses were performed on male and female traces. Results were considered statistically significant if $t \geq 1.96$. Student's $t$ test was used to analyze 5 -HT fiber staining on spinal cord tissue. Welch's $t$ test for unequal variances was used to analyze staining of WFA. Results were considered statistically significant if $p<0.05$. Investigators were blinded until all diaphragmatic EMG and histology analyses were complete. The mean difference (MD) and 95\% confidence interval (Cl) were calculated to provide an estimate of the range of possible differences between groups (Table 2).

\section{Results}

\section{Respiratory motor plasticity in $\mathrm{C} 2$ hemisected humanized $A P O E$ mice}

At three months of age, male and female mice received a left C2 hemisection by making an incision from the midline to the left lateral edge of the spinal cord just caudal to the $\mathrm{C} 2$ dorsal roots. This injury effectively disrupts the neural circuitry that descends from the ipsilateral medullary respiratory nuclei to phrenic motor neurons on the left side (Fig. 1B). At the time of injury, hemisection was visually confirmed by observing the thorax of each mouse to ensure that only the right side of the thorax continued rhythmically expanding with each breath. Injury completeness was histologically confirmed on killing of a subset of mice $(n=16)$ using cresyl violet (Fig. 1C). All mice were homozygous for human $\varepsilon 3$ or $\varepsilon 4$ alleles expressed under control of the murine APOE promoter as described previously (Sullivan et al., 1997; Knouff et al., 1999). At three weeks postinjury, mice were exposed to $\mathrm{IH}$. This consisted of 3 hypoxic $\left(11 \% \mathrm{O}_{2}\right)$ bouts of 5 -min duration separated by 5 min of normoxia as illustrated in Figure 1. We evaluated the breathing response to $\mathrm{IH}$ by concurrently recording diaphragmatic EMG, which continued for $1 \mathrm{~h}$ following the final hypoxic bout. Amplitude of diaphragmatic bursts was quantified while blinded and then grouped according to $A P O E$ genotype. No difference was found in the response to $\mathrm{IH}$ between mice expressing $\varepsilon 3$ or $\varepsilon 4$ (RMANOVA $p=0.741$; Fig. $1 D$ ). All animals appear to experience an initial decrease in diaphragmatic activity during the first hypoxic bout. Breathing in both apoE3 and apoE4 mice remained constant once the $\mathrm{IH}$ protocol ended (Fig. 1D).

Previous studies in rodents (Bach and Mitchell, 1996; Baker and Mitchell, 2000; for review, see Fuller et al., 2000; Terada et al., 2008) have shown that IH treatment gives rise to an augmentation of breathing activity that characterizes long term facilitation (LTF). We therefore compared amplitude at the beginning of $\mathrm{IH}$ and $40 \mathrm{~min}$ after the final bout of hypoxia to determine whether breathing activity increased in response to $\mathrm{IH}$. Neither genotype exhibited significant augmentation of diaphragmatic activity at 40-min posthypoxia, indicative of a lack of LTF in the humanized mice (paired $t$ test E3 $p=0.741$, $\mathrm{E} 4 p=0.405$; Fig. $1 E$ ).

\section{Sex differences in apoE modulation of LTF}

To investigate sex-dependent influences of $A P O E$ genotype on LTF, we separated data from males and females for independent analysis. Animals were weighed every day for the first $4 d$ after injury and then once a week until diaphragmatic EMG recordings were performed. When comparing weights over time after injury, there was no significant difference between genotypes in male $(p=0.16)$ or female $(p=0.65)$ mice (data not shown). Figure $2 A$ shows representative traces from male apoE3 and E4 mice. As evidenced in these traces, both genotypes exhibited a decrease in frequency over time after $\mathrm{IH}$. However, there was no significant genotype effect on the magnitude of this decrease (RMANOVA, $p=0.846$; Fig. 2A; Extended Data Fig. 2-1A). Previous studies in rats (Warren et al., 2018) have reported no spontaneous recovery in the paralyzed hemidiaphragm even chronically after $\mathrm{C} 2$ hemisection. In contrast, the overwhelming majority of the 32 mice used in the current study showed spontaneous functional recovery of the paralyzed mouse hemidiaphragm. Considering all males and females from 
A

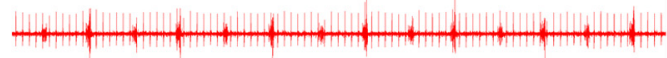

E4

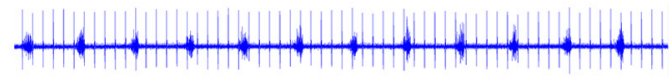

B

$1^{\text {st }}$ normoxia

E3

E4

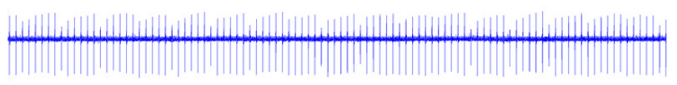

C

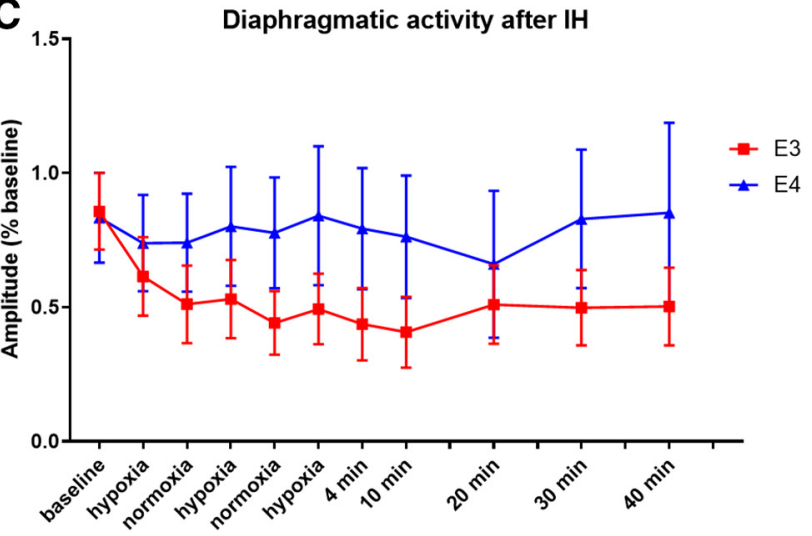

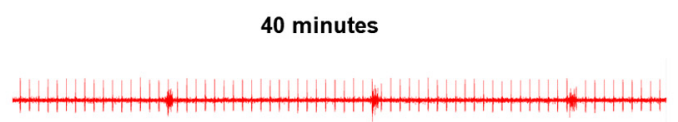

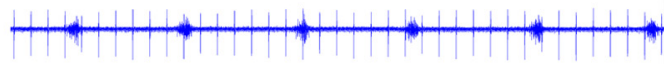

1 sec.

40 minutes

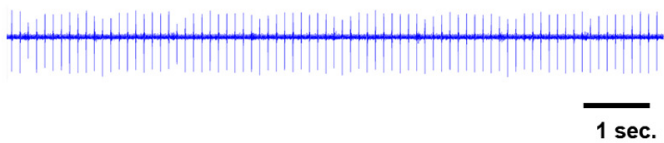

D

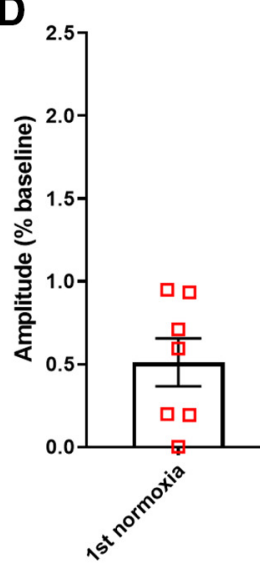

Diaphragmatic activity

ㅁ $\mathrm{E3}$

$\triangle \mathrm{E} 4$

Figure 2. ApoE3 males demonstrate a trend of decreasing diaphragmatic activity in response to IH. $\boldsymbol{A}$, Representative traces of diaphragmatic activity during the first normoxic bout and $40 \mathrm{~min}$ after $\mathrm{IH}$. $\boldsymbol{B}$, Representative traces from male mice that had no spontaneous recovery. C, Quantification of diaphragmatic activity over time during and after IH. Amplitude of diaphragmatic bursts is not significantly different between E3 and E4 animals. $\boldsymbol{D}$, Quantification of diaphragmatic activity during the first normoxic bout and $40 \mathrm{~min}$ after $\mathrm{IH}(d$. RMANOVA E3/E3 $t=0.03, \mathrm{MD}=0.0086, \mathrm{Cl}=-0.295-0.36 ;$ e. E3/E4 norm $t=-0.55, \mathrm{MD}=0.23, \mathrm{Cl}=$ $-1.18-0.078 ; f$. E3/E4 $40 \min t=-0.91, \mathrm{MD}=0.35, \mathrm{Cl}=-1.54$ to $-0.28 ; g$. E4/E4 $t=-0.67, \mathrm{MD}=0.11, \mathrm{Cl}=-0.41-0.63$ ). Bars show mean and SEM values.

which we recorded diaphragmatic EMGs, only two mice displayed no spontaneous recovery: one male of each genotype (Fig. 2B). Quantification of the diaphragmatic EMG data demonstrates that males expressing the $\varepsilon 3$ allele display a decline in the amplitude of diaphragmatic bursting beginning in the first hypoxic bout and persisting throughout the recording period (Fig. 2C). Although this deterioration of activity did not reach statistical significance (RMANOVA, $t=0.03$ ), it is worthwhile to highlight how the apoE3 males diverged from apoE4, which demonstrate slightly heightened activity at $40 \mathrm{~min}$ post-IH (RMANOVA, $t=-0.65$; Fig. $2 C, D$ ).

Analysis of diaphragmatic EMGs in female mice of both genotypes showed a similar negative trend in the breathing frequency induced by IH (RMANOVA, $p=0.673$; Fig.
3A; Extended Data Fig. 3-1). A subset of mice displayed a complete loss of diaphragmatic activity following hypoxic exposure. We refer to these animals as "non-responders." Three non-responders emerged in the apoE4 group, while none were observed in the mice that expressed $\varepsilon 3$ (representative trace shown in Fig. $3 B$ ). However, unlike the male mice, all females demonstrated spontaneous recovery before IH (data not shown). Quantification of diaphragmatic burst amplitude in females that maintained diaphragmatic activity after $\mathrm{IH}$ showed that apoE3 mice responded to $\mathrm{IH}$ with an initial decrease in burst amplitude. This decline was temporary and activity returned to near baseline levels by 40 min (Fig. 3C). However, apoE4 females exhibited an immediate reduction in burst amplitude that is still evident the end of the recording period. At 
A

E3

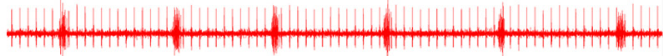

E4

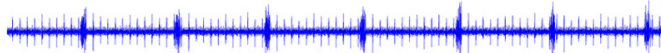

B

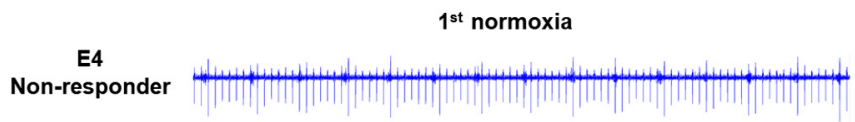

C

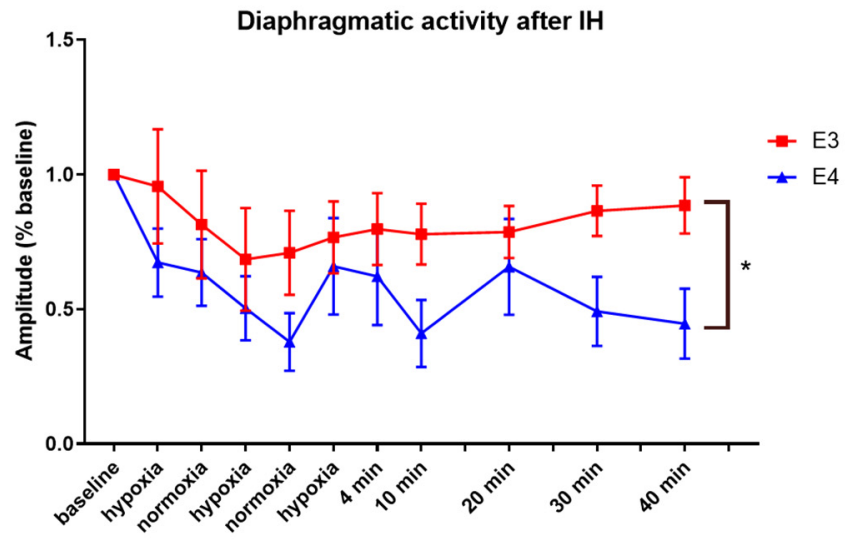

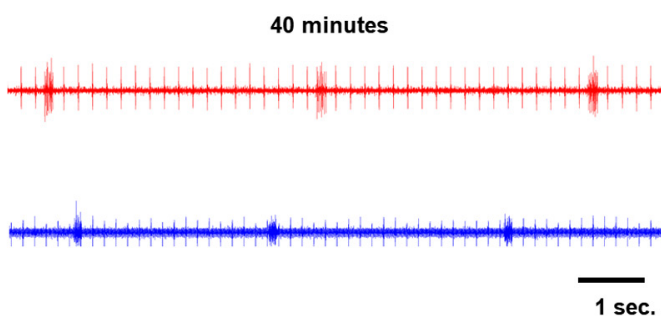

40 minutes

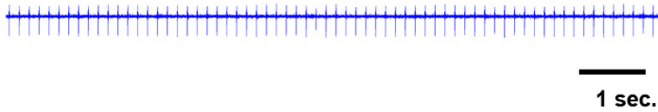

D

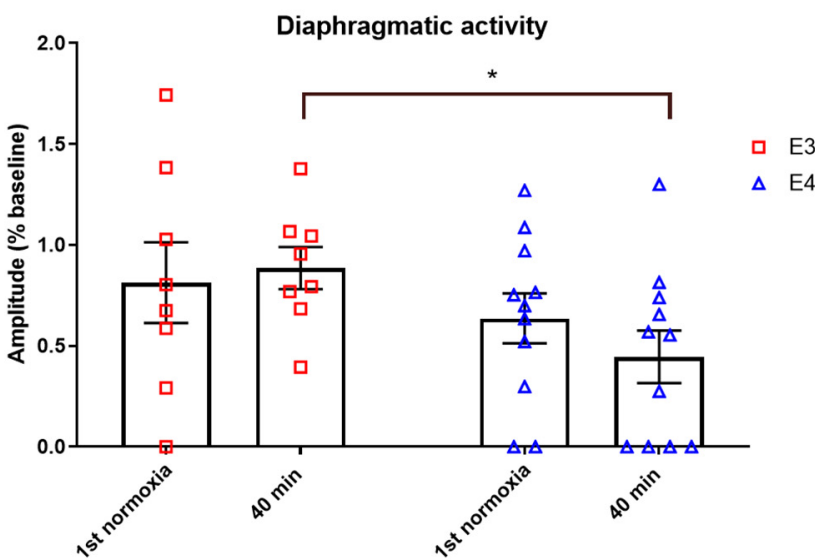

Figure 3. ApoE4 females display significantly less diaphragmatic activity than E3 females after IH. $\boldsymbol{A}$, representative traces of diaphragmatic activity during the first normoxic bout and $40 \mathrm{~min}$ after $\mathrm{IH}$. $\boldsymbol{B}$, Representative traces from an apoE4 female non-responder. C, Quantification of diaphragmatic activity over time during and after $\mathrm{IH}$. Amplitude of diaphragmatic bursts are significantly greater in E3 females than in E4. $D$, Quantification of diaphragmatic activity during the first normoxic bout and 40 min after IH $(h$. RMANOVA E3/E3 $t=-0.32, \mathrm{MD}=0.071, \mathrm{Cl}=-0.75-0.11 ; i$. E3/E4 normoxia $t=0.84, \mathrm{MD}=0.18, \mathrm{Cl}=0.43-1.25 ; j$. E3/E4 $40 \min t=2.08, \mathrm{MD}=0.44, \mathrm{Cl}=1.67-2.49 ; \mathrm{k} . \mathrm{E} 4 / \mathrm{E} 4 t=1.01, \mathrm{MD}=0.19, \mathrm{Cl}=0.64-1.38)$. Asterisk represents statistical significance $(t>1.96)$ Bars show mean and SEM values.

40 min post- $\mathrm{H}$, breathing of apoE4 females is significantly depressed compared with that of apoE3's at the same time point (mixed model RMANOVA $t=2.08$; Fig. $3 C, D$ ). Consistent with the combined data, none of the female mice expressing human APOE developed the gradual and prolonged breathing augmentation that is characteristic of LTF.

When animals are challenged with a brief bout of hypoxia, feedback from peripheral chemoreceptors induces an augmentation of respiratory output. This change in ventilation is known as the hypoxic ventilatory response (HVR; described by Pamenter and Powell, 2016). During the hypoxic bouts of IH treatment, all apoE mice exhibited a decline in diaphragmatic activity instead of the expected amplification. To further investigate the HVR in our humanized mice, we exposed an additional, smaller cohort of mice to a 10-min bout of hypoxia and assessed the changes in amplitude and frequency of diaphragmatic bursting. No females of either genotype displayed an increase or decrease in amplitude, but breath frequency began to decline by the end of the hypoxic period in those expressing $\varepsilon 4$ (Extended Data Fig. 3-1B,C). In male mice expressing $\varepsilon 3$, there was a sharp decline in both amplitude and frequency of diaphragmatic firing in response to hypoxia such that breathing activity was abolished at $10 \mathrm{~min}$. Conversely, amplitude and frequency in apoE4 males remained constant during hypoxia (Extended Data Fig. 2-1B,C).

\section{Perineuronal net upregulation and serotonergic sprouting in the phrenic motor nucleus}

Secretion of CSPGs, a component of the perineuronal net (PNN), is upregulated after $\mathrm{SCl}$ in wild-type animals, creating a barrier to plasticity, regeneration, and sprouting (Tom et al., 2009; Alilain et al., 2011). Thus far, it is unknown whether the magnitude of this upregulation is modulated by human $A P O E$ genotype. Therefore, we used WFA staining to compare the amount of PNN present in injured spinal cords at the C4 level to determine whether the $\mathrm{IH}$-induced reduction in diaphragmatic activity observed in E4 females was correlated with increased 


\section{A}

E3

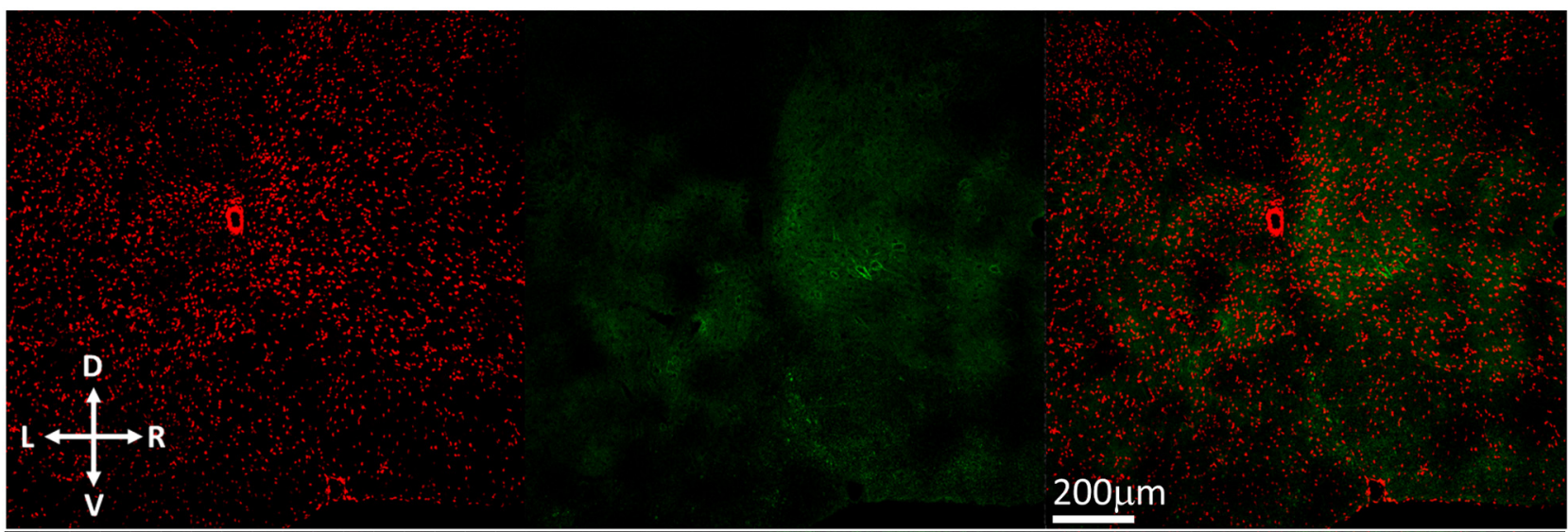

E4

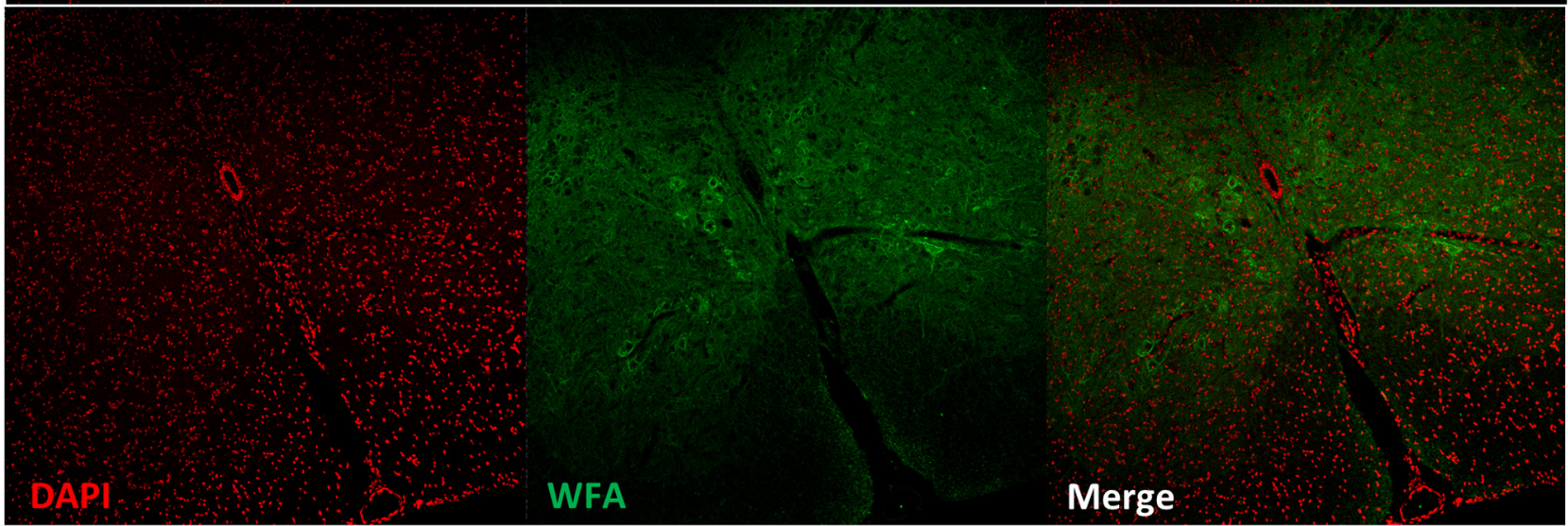

E3

B

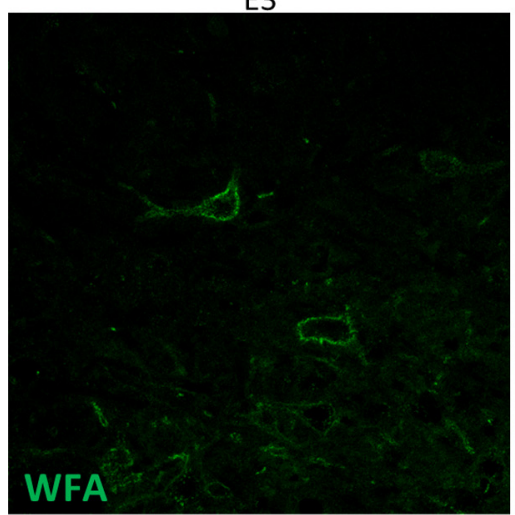

E4

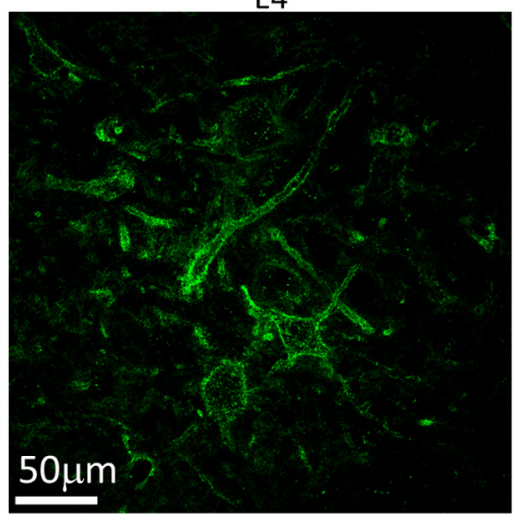

Ipsilateral WFA

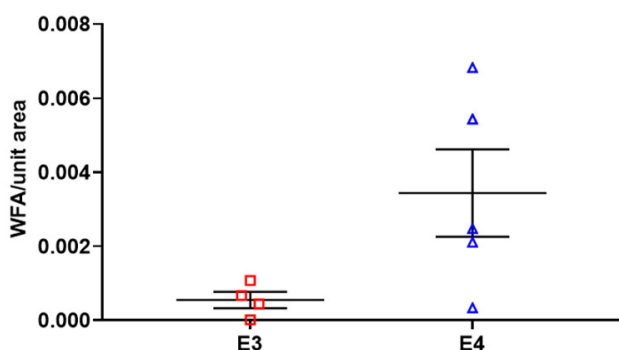

Figure 4. E4 females have higher levels of PNN. $\boldsymbol{A}$, Representative images of WFA staining at the C4 spinal cord level (DAPI is in red, WFA is in green). $\boldsymbol{B}$, Higher-magnification images show the PNN surrounding putative phrenic motor neurons. $\boldsymbol{C}$, Quantification of WFA indicates that apoE4 mice express more WFA than E3 mice, although this trend is not statistically significant $(I$. Welch's $t$ test $p=0.0697, \mathrm{MD}=0.0029, \mathrm{Cl}=-0.00036-0.0061)$. Bars represent mean \pm SEM.

amounts of inhibitory PNN. Indeed, we found that apoE4 females tended to have a higher density of WFA around the phrenic motor nucleus after injury, although this trend did not reach significance (Welch's $t$ test, $p=0.0697$; Fig. $4 A-C)$.

The PNN can limit 5-HT sprouting after injury (Alilain et al., 2011). To determine whether differences in respiratory motor plasticity observed in females were because of the amount of serotonin at the level of the phrenic motor nucleus after $\mathrm{C} 2 \mathrm{Hx}$, serotonergic fibers were labeled and quantified in the ventral horn ipsilateral to injury. Serotonergic sprouting after injury has previously been correlated with the restoration of breathing function and enhancement of LTF (Golder and Mitchell, 2005). We postulated that dampened respiratory plasticity in $\varepsilon 4 \mathrm{fe}-$ males may be because of a lack of serotonergic sprouting after injury. Surprisingly, quantification of 5-HT+ fibers ipsilateral to injury revealed enhanced serotonergic sprouting in apoE4 females compared with apoE3 (Student's $t$ test, $p=0.0193$; Fig. $5 A-C$ ). This contradicted our 
A

E3

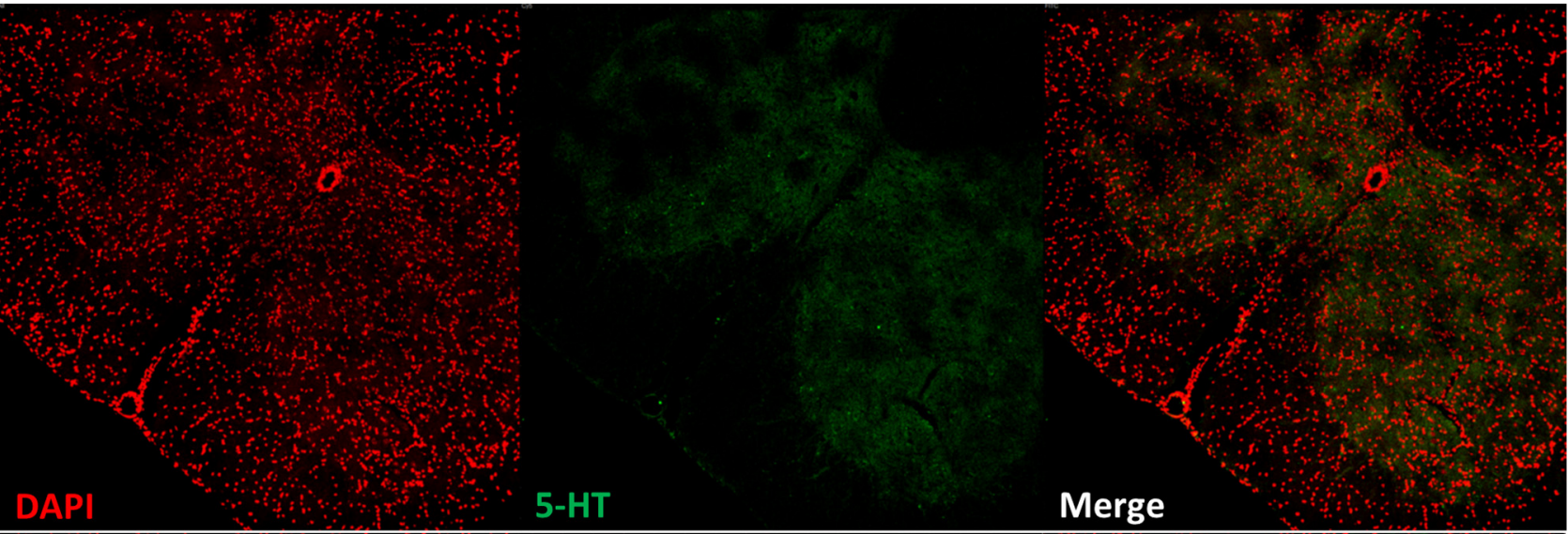

E4

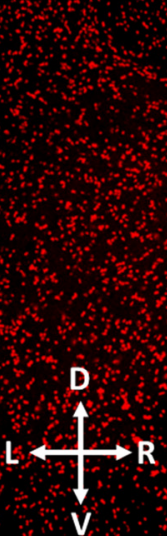

B
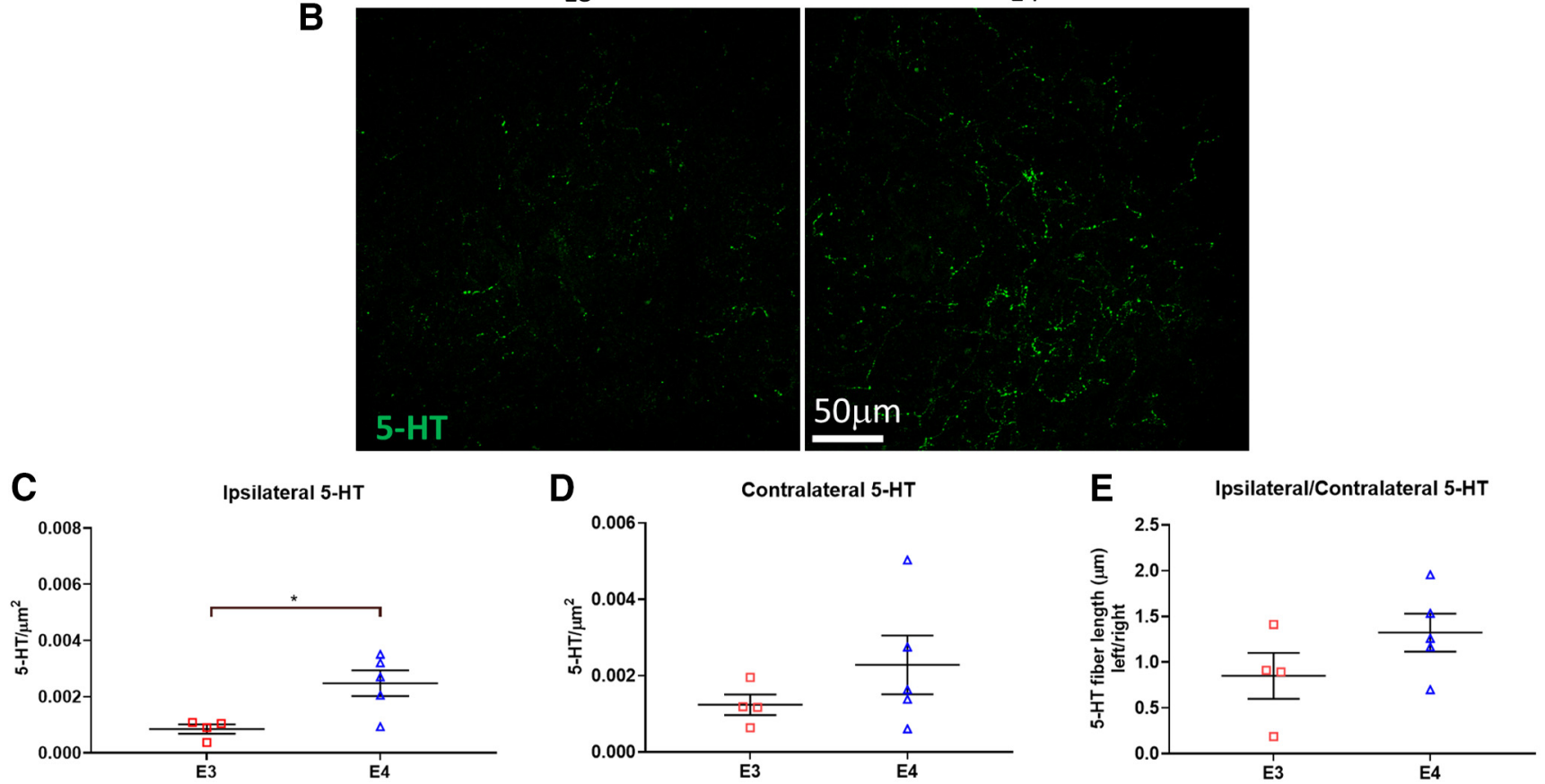

Figure 5. E4 females have higher density of spinal 5-HT fibers. $\boldsymbol{A}$, Representative images of stained 5-HT fibers in the C4 spinal cord level. $\boldsymbol{B}$, Higher magnification shows individual 5-HT fibers in the area of the putative PMN. $\boldsymbol{C}$, Significantly more serotonergic fibers are found ipsilateral to injury in apoE4 females $(\mathrm{m}$. Student's $t$ test $p=0.0193, \mathrm{MD}=0.0016, \mathrm{Cl}=0.00036-0.0029)$. $\boldsymbol{D}, 5-\mathrm{HT}$ fibers contralateral to injury at the C4 level ( $n$. Student's $t$ test $p=0.286, \mathrm{MD}=0.00,104, \mathrm{Cl}=-0.0011-0.0032)$. $\boldsymbol{E}$, Ipsilateral $5-\mathrm{HT}$ staining normalized to contralateral $(0$. Student's $t$ test $p=0.187, \mathrm{MD}=0.47, \mathrm{Cl}=-0.29-1.24)$. Asterisk represents statistical significance $(p<0.05)$. Bars represent mean $\pm \mathrm{SEM}$. 
expectation that a blunted respiratory response to $\mathrm{IH}$ would correspond with attenuated fiber sprouting after injury. Quantification of 5-HT fibers contralateral to injury showed no significant difference between E3 and E4 females, although E4 tended to have more 5-HT staining (Student's $t$ test, $p=0.286$; Fig. 5D). After injury, E4 females had more 5-HT fibers ipsilateral than contralateral to injury, although this did not reach statistical significance (Student's $t$ test, $p=0.187$; Fig. $5 E$ ).

\section{Discussion}

This study represents the first investigation into human genetic influences on the efficacy of experimental therapeutic strategies for $\mathrm{SCl}$. Our results demonstrate that individuals' propensity for initiating beneficial neuroplastic responses to therapeutic $\mathrm{IH}$ is modified by sex and $A P O E$ genotype. By using a well-described model of $\mathrm{SCl}$ and spinally-mediated motor plasticity, we provide evidence to support the hypothesis that human genetic factors that are not represented by preclinical animal models limit the potential for recovery after SCl. Our physiology and histology data indicate that sex and genotype influence the CNS response to injury and therapeutic intervention, which poses a significant challenge to translating onesize-fits-all treatment strategies.

\section{APOE genotype and respiratory motor plasticity}

Recovery of breathing function is a top priority for people living with cSCl (Anderson, 2004). IH has promising potential to enhance spinal plasticity for the restoration of a variety of motor behaviors, including breathing (Fuller et al., 2003; Lovett-Barr et al., 2012; Trumbower et al., 2012). Studies by Wadhwa et al. (2008) and Tester et al. (2014) in human participants have demonstrated that ventilatory LTF is expressed by both male and female subjects, even when living with a chronic SCl. However, to our knowledge, the interaction of sex and genetic factors remains unexplored in the LTF literature. Preclinical studies that have addressed the impact of sex on respiratory motor plasticity revealed that sex hormone levels have significant ramifications for the potential to induce plasticity, likely because of the interaction of sex hormones and the serotonergic system (Zabka et al., 2001a,b, 2003). Additionally, Baker-Herman et al. (2010) found that rat strains of different genetic backgrounds vary in their responses to $\mathrm{IH}$, which was associated with differences in the expression of $5-\mathrm{HT}_{2 \mathrm{~A}}$ receptors on $\mathrm{PMNs}$.

To further address how genetic variability impacts spinal plasticity, we examined the efficacy of IH for inducing LTF in targeted replacement mice expressing the human apoE $\varepsilon 3$, and $\varepsilon 4$ alleles. Since apoE first gained notoriety as a genetic marker for Alzheimer's disease (AD), an extensive body of literature has investigated the impact of the apoE isoforms in the brain. The $\varepsilon 4$ allele increases the risk of developing $A D$ and lowers the age of onset in a dose-dependent manner (Corder et al., 1993; Saunders et al., 1993). E4 carriers display mitochondrial dysfunction, aggravated neuroinflammatory responses to CNS damage, loss of blood brain barrier integrity, and impaired synaptic plasticity (Safieh et al., 2019). These factors are also key determinants for the extent of tissue damage, plasticity, regeneration, and the potential for recovery after SCI (Noble and Wrathall, 1989; Sullivan et al., 2007; Alilain and Goshgarian, 2008; Kigerl et al., 2009).

ApoE further became a gene of interest in our investigation after studies in human $\mathrm{SCl}$ patients found that people who carried the $\varepsilon 4$ allele experienced significantly less motor recovery than non-carriers, despite spending more time in rehabilitation (Jha et al., 2008; Sun et al., 2011). ApoE4 is known to curb recycling of NMDA and AMPA receptors to the postsynaptic membrane and reduces levels of BDNF in the CNS (Chen et al., 2010; Chhibber and Zhao, 2017; Sen et al., 2017). Since LTF requires BDNF signaling and activation of NMDA receptors, individuals expressing the $\varepsilon 4$ allele may have a constrained response to $\mathrm{IH}$ (BakerHerman et al., 2004; McGuire et al., 2005). However, our data demonstrates that mice expressing human apoE isoforms did not differ in their diaphragmatic response to $\mathrm{IH}$, indicating that there may be no effect on LTF when APOE genotype is the sole variable being considered.

The lack of divergence between genotypes and the absence of augmented diaphragmatic activity in response to $\mathrm{IH}$ could also be because of metabolic changes. Many protocols for the induction of LTF, which are primarily conducted in rats, include the measurement of $\mathrm{pCO}_{2}$ throughout recording (Hayashi et al., 1993; Bach and Mitchell, 1996). This measurement provides a gauge of how metabolism is changing as a result of hypoxic hypometabolism: instead of increasing respiratory activity, small mammals respond to hypoxic conditions by downregulating their metabolic rate to reduce oxygen consumption (Hill, 1959). Because we did not measure $\mathrm{pCO}_{2}$ during EMG recordings because of the low blood volume of mice, we were unable to control for changes in metabolic rate, which could have prevented $\mathrm{H}$-induced breathing augmentation. However, we do not think that hypometabolism was responsible for masking genotype effects since differences emerged when animals were grouped according to sex.

Interestingly, mice displayed a decrease in ipsilateral hemidiaphragmatic activity during hypoxic bouts, instead of the heightened activity that is typical of the HVR observed in rats (Pamenter and Powell, 2016). Very little data are available on the respiratory response to $\mathrm{IH}$ and manifestation of LTF in C2 hemisected mice, although Minor et al. (2006) demonstrated the presence and viability of the murine crossed phrenic pathway (CPP), the anatomic substrate that mediates LTF (Golder and Mitchell, 2005). The few studies performed in mice are variable in IH protocols and methods of assessing LTF (Terada et al., 2008; Hickner et al., 2014; EIMallah et al., 2016). Our HVR data indicates that mice respond to bouts of hypoxia differently than rats, but additional experiments are needed to characterize this phenomenon. Considering the availability of transgenic mouse models, a standardized protocol for inducing and evaluating LTF in murine models would be extremely advantageous for studying how human genes influence spinally-mediated breathing plasticity.

\section{Sex effects}

Another explanation for the lack of observable differences between genotypes is that they could be masked 
by sex effects. APOE has long been studied in the Alzheimer's field, where genotype influences are known to be modulated by sex. While expression of the $\varepsilon 4$ allele increases the risk of developing $A D$ in both males and females, this risk is greater in females (Duara et al., 1996; Altmann et al., 2014). In rodents, apoE4-related deficits in learning and memory are aggravated in females, indicating that synaptic plasticity in the brain is impaired in a sex-dependent manner (Raber et al., 1998; Kulkarni et al., 2020). The implication for similar trends in spinally-mediated plasticity led to further analysis of our data, in which the influence of genotype was investigated separately in males and females.

Diaphragmatic EMG recordings from females revealed a significant difference between the response of apoE3 and apoE4 animals; 40 min after $\mathrm{IH}$, diaphragmatic activity was significantly depressed in females expressing $\varepsilon 4$. Consistent with findings in the brain, this demonstrates that apoE4 females have a limited propensity for plasticity in the spinal cord. This pattern was not reflected in male mice. In contrast with the current body of literature, we show that apoE3 males experience a barrier to synaptic plasticity, as they display the largest decrease in diaphragmatic activity.

To our knowledge, apoE3-associated attenuations of plasticity have never been reported in young adult mice. Since the majority of apoE literature describes its effects on the brain and the periphery, it is possible that our results are because of a unique action of apoE in the spinal cord. The mechanism behind induction of LTF in the bulbospinal breathing circuitry is similar to that of long-term potentiation (LTP) in the hippocampus: both rely on synaptic strengthening brought about by activation of postsynaptic NMDA receptors and signaling through ERK (English and Sweatt, 1997; McGuire et al., 2005; Hoffman et al., 2012). Disparate results from a variety of studies in targeted replacement mice suggest apoE4 can be detrimental or beneficial to LTP depending on brain region, sex, and age (Levi et al., 2003; Kitamura et al., 2004; Trommer et al., 2004; Korwek et al., 2009). Taking this into account, it is less surprising to see that apoE3 also has the potential to augment or impede similar mechanisms of plasticity. This effect may also be dependent on age and region of the CNS.

\section{The inhibitory PNN and serotonergic presence after C2Hx in targeted replacement mice}

Following $\mathrm{SCl}$, there is a dramatic upregulation of inhibitory CSPGs at the site of injury and in denervated targets (Bradbury et al., 2002; Massey et al., 2008; Alilain et al., 2011). Indeed, after dorsal column transections, there is an upregulation of the CSPG-containing PNN around sensory nuclei (Massey et al., 2008) and in previous studies using lateral C2 hemisections, PMNs became further encased by CSPGs and the PNN (Alilain et al., 2011). Despite the abundance of evidence implicating the importance of CSPGs in limiting plasticity, regeneration, and recovery (for review, see Tran et al., 2018); the influence of human genetics (and $A P O E$ alleles) on PNN structure and neuronal sprouting in the injured spinal cord has never been investigated. However, a study of human brains indicated that apoE4 augments expression of a CSPG known as brevican in the brain of Alzheimer's patients, which could explain the more extensive staining of PNN observed in E4 mice (Conejero-Goldberg et al., 2015).

Indeed, our findings indicate that apoE4 females exhibit a greater density of the PNN in the ventral horn region containing PMNs after injury. Although PMNS were not discreetly labeled, upregulation of the PNN at the C4 level ipsilateral to injury suggests that deficits in respiratory motor plasticity could be a consequence of the PNN's numerous influences on CNS function and plasticity. Appearance of the PNNs containing CSPGs during development ends critical periods in which experience-dependent plasticity shapes neural circuitry. Degradation of CSPGs reopens this critical period and restores synaptic plasticity in the adult CNS (Pizzorusso et al., 2002). Following lateral spinal hemisection, increasing densities of CSPG molecules impede calcium diffusion and block action potential conduction in intact axons that are spared by the injury (Hrabetová et al., 2009; Hunanyan et al., 2010). These molecules also create an inhibitory microenvironment that prevents sprouting and regeneration of fibers in the injured spinal cord, including 5-HT fibers that have the potential to enhance functional recovery after experimental SCI (Alilain et al., 2011; Warren et al., 2018; Warren and Alilain, 2019).

Since serotonergic signaling at the level of PMNs is crucial to induction of LTF (Bach and Mitchell, 1996), we quantified 5-HT staining around the putative PMN in spinal cords from E3 and E4 females. Density of 5-HT fibers was higher in E4 females both contralateral and ipsilateral to injury, although this difference did not reach statistical significance on the contralateral side. This indicates that compared with apoE3, apoE4 females may have greater serotonergic innervation of the PMN in the absence of injury. However, additional studies are needed to determine whether females expressing $\varepsilon 4$ have greater serotonergic innervation before injury, as well as after $\mathrm{C} 2 \mathrm{Hx}$. Indeed, if this pattern is consistent regardless of injury status, increased 5-HT fiber density could represent a compensatory mechanism that maintains motor neuron excitability in these animals while combatting the loss of synaptic integrity over time that is observed in E4 animals (Klein et al., 2010). The observed attenuation of LTF after injury may therefore be because of apoE4-dependent decreases in 5-HT receptor expression on PMNs, or a result of alterations downstream of 5-HT receptor activation in the signaling pathways that are necessary for the induction of LTF.

Although the higher density of PNN in E4 females is not associated with a decrease in the amount of 5-HT at the level of the PMN after injury, the CSPG-containing PNN could still play a role in abrogating respiratory motor plasticity. Further investigations are needed to determine whether CSPGs block ion flow in spared axons such as the CPP after cervical hemisection similar to the inhibition observed after thoracic injury (Hrabetová et al., 2009; Hunanyan et al., 2010). Previous studies have shown that degradation of CSPGs leads to increased presence of 5- 
$\mathrm{HT}$ around PMNs, which is associated with recovery of breathing function. However, these studies did not address at the effect of CSPG upregulation or degradation on glutamatergic sprouting or regeneration (Alilain et al., 2011; Warren et al., 2018; Warren and Alilain, 2019). Therefore, alterations in glutamatergic innervation of PMNs could also contribute to the enhancement of diaphragmatic function demonstrated in these studies. Although E4 females displayed more 5-HT fibers than E3 females, further examination of glutamatergic axon regeneration and sprouting, as well as how enzymatic degradation of CSPGs alters this innervation, could provide insight into whether PNN upregulation contributes to a lack of respiratory motor plasticity in females expressing $\varepsilon 4$.

The primary goal of this study was to investigate the role of genetic variability in determining an individual's propensity for spinal plasticity and recovery of breathing function after SCl. Preclinical studies typically test therapeutic approaches in a homogenous group of animals, which does not represent the diversity found in the human population. As IH and other therapeutics enter clinical trials, their efficacy for treating a heterogeneous population is an important consideration. Overall, our findings that sex and APOE genotype modulate the response to therapeutic $\mathrm{IH}$, along with the current dearth of successful treatment strategies for $\mathrm{SCl}$, emphasizes the importance of advancing personalized medicine to improve outcomes for injured individuals.

\section{References}

Ahuja CS, Nori S, Tetreault L, Wilson J, Kwon B, Harrop J, Choi D, Fehlings MG (2017) Traumatic spinal cord injury-repair and regeneration. Neurosurgery 80:S9-S22.

Alilain WJ, Goshgarian HG (2008) Glutamate receptor plasticity and activity-regulated cytoskeletal associated protein regulation in the phrenic motor nucleus may mediate spontaneous recovery of the hemidiaphragm following chronic cervical spinal cord injury. Exp Neurol 212:348-357.

Alilain WJ, Horn KP, Hu H, Dick TE, Silver J (2011) Functional regeneration of respiratory pathways after spinal cord injury. Nature 475:196-200.

Alp E, Voss A (2006) Ventilator associated pneumonia and infection control. Ann Clin Microbiol Antimicrob 5:7.

Altmann A, Tian L, Henderson VW, Greicius MD; Alzheimer's Disease Neuroimaging Initiative Investigators (2014) Sex modifies the APOE-related risk of developing Alzheimer disease. Ann Neurol 75:563-573.

Anderson KD (2004) Targeting recovery: priorities of the spinal cordinjured population. J Neurotrauma 21:1371-1383.

Bach KB, Mitchell GS (1996) Hypoxia-induced long-term facilitation of respiratory activity is serotonin dependent. Respir Physiol 104:251-260.

Baker TL, Mitchell GS (2000) Episodic but not continuous hypoxia elicits long-term facilitation of phrenic motor output in rats. J Physiol 529:215-219.

Baker-Herman TL, Fuller DD, Bavis RW, Zabka AG, Golder FJ, Doperalski NJ, Johnson RA, Watters JJ, Mitchell GS (2004) BDNF is necessary and sufficient for spinal respiratory plasticity following intermittent hypoxia. Nat Neurosci 7:48-55.

Baker-Herman TL, Bavis RW, Dahlberg JM, Mitchell AZ, Wilkerson JER, Golder FJ, MacFarlane PM, Watters JJ, Behan M, Mitchell GS (2010) Differential expression of respiratory long-term facilitation among inbred rat strains. Respir Physiol Neurobiol 170:260267.
Bergofsky EH (1964) Mechanism for respiratory insufficiency after cervical cord injury; a source of alveolar hypoventilation. Ann Intern Med 61:435-447.

Boyles JK, Pitas RE, Wilson E, Mahley RW, Taylor JM (1985) Apolipoprotein $E$ associated with astrocytic glia of the central nervous system and with nonmyelinating glia of the peripheral nervous system. J Clin Invest 76:1501-1513.

Bradbury EJ, Moon LDF, Popat RJ, King VR, Bennett GS, Patel PN, Fawcett JW, McMahon SB (2002) Chondroitinase ABC promotes functional recovery after spinal cord injury. Nature 416:636-640.

Chen MS, Huber AB, van der Haar ME, Frank M, Schnell L, Spillmann AA, Christ F, Schwab ME (2000) Nogo-A is a myelin-associated neurite outgrowth inhibitor and an antigen for monoclonal antibody IN-1. Nature 403:434-439.

Chen Y, Durakoglugil MS, Xian X, Herz J (2010) ApoE4 reduces glutamate receptor function and synaptic plasticity by selectively impairing ApoE receptor recycling. Proc Natl Acad Sci USA 107:12011-12016.

Chhibber A, Zhao L (2017) ER $\beta$ and ApoE isoforms interact to regulate BDNF-5-HT2A signaling and synaptic function in the female brain. Alzheimers Res Ther 9:79.

Conejero-Goldberg C, Hyde TM, Chen S, Herman MM, Kleinman JE, Davies P, Goldberg TE (2015) Cortical transcriptional profiles in APOE4 carriers with Alzheimer's disease: patterns of protection and degeneration. J Alzheimers Dis 48:969-978.

Corder EH, Saunders AM, Strittmatter WJ, Schmechel DE, Gaskell PC, Small GW, Roses AD, Haines JL, Pericak-Vance MA (1993) Gene dose of apolipoprotein E type 4 allele and the risk of Alzheimer's disease in late onset families. Science 261:921-923.

David S, Aguayo AJ (1981) Axonal elongation into peripheral nervous system "bridges" after central nervous system injury in adult rats. Science 214:931-933.

DeVivo MJ, Ivie CS (1995) Life expectancy of ventilator-dependent persons with spinal cord injuries. Chest 108:226-232.

Duara R, Barker WW, Lopez-Alberola R, Loewenstein DA, Grau LB, Gilchrist D, Sevush S, St George-Hyslop S (1996) Alzheimer's disease: interaction of apolipoprotein $\mathrm{E}$ genotype, family history of dementia, gender, education, ethnicity, and age of onset. Neurology 46:1575-1579.

EIMallah MK, Stanley DA, Lee K-Z, Turner SMF, Streeter KA, Baekey DM, Fuller DD (2016) Power spectral analysis of hypoglossal nerve activity during intermittent hypoxia-induced long-term facilitation in mice. J Neurophysiol 115:1372-1380.

English JD, Sweatt JD (1997) A requirement for the mitogen-activated protein kinase cascade in hippocampal long term potentiation. J Biol Chem 272:19103-19106.

Fouad K, Popovich PG, Kopp MA, Schwab JM (2020) The neuroanatomical-functional paradox in spinal cord injury. Nat Rev Neurol 17:53-62.

Fuller DD, Bach KB, Baker TL, Kinkead R, Mitchell GS (2000) Long term facilitation of phrenic motor output. Respir Physiol 121:135146.

Fuller DD, Johnson SM, Olson EB, Mitchell GS (2003) Synaptic pathways to phrenic motoneurons are enhanced by chronic intermittent hypoxia after cervical spinal cord injury. J Neurosci 23:29933000.

Golder FJ, Mitchell GS (2005) Spinal synaptic enhancement with acute intermittent hypoxia improves respiratory function after chronic cervical spinal cord injury. J Neurosci 25:2925-2932.

Hayashi F, Coles SK, Bach KB, Mitchell GS, McCrimmon DR (1993) Time-dependent phrenic nerve responses to carotid afferent activation: intact vs. decerebellate rats. Am J Physiol 265:R811-R819.

Hayes HB, Jayaraman A, Herrmann M, Mitchell GS, Rymer WZ, Trumbower RD (2014) Daily intermittent hypoxia enhances walking after chronic spinal cord injury: a randomized trial. Neurology 82:104-113.

Hickner S, Hussain N, Angoa-Perez M, Francescutti DM, Kuhn DM, Mateika JH (2014) Ventilatory long-term facilitation is evident after initial and repeated exposure to intermittent hypoxia in mice 
genetically depleted of brain serotonin. J Appl Physiol (1985) 116:240-250.

Hill JR (1959) The oxygen consumption of new-born and adult mammals. Its dependence on the oxygen tension in the inspired air and on the environmental temperature. J Physiol 149:346-373.

Hoffman MS, Nichols NL, Macfarlane PM, Mitchell GS (2012) Phrenic long-term facilitation after acute intermittent hypoxia requires spinal ERK activation but not TrkB synthesis. J Appl Physiol (1985) 113:1184-1193.

Hrabetová S, Masri D, Tao L, Xiao F, Nicholson C (2009) Calcium diffusion enhanced after cleavage of negatively charged components of brain extracellular matrix by chondroitinase ABC. J Physiol 587:4029-4049.

Huie JR, Morioka K, Haefeli J, Ferguson AR (2017) What is being trained? How divergent forms of plasticity compete to shape locomotor recovery after spinal cord injury. J Neurotrauma 34:18311840.

Hunanyan AS, García-Alías G, Alessi V, Levine JM, Fawcett JW, Mendell LM, Arvanian VL (2010) Role of chondroitin sulfate proteoglycans in axonal conduction in mammalian spinal cord. J Neurosci 30:7761-7769.

Jack AS, Hurd C, Martin J, Fouad K (2020) Electrical stimulation as a tool to promote plasticity of the injured spinal cord. J Neurotrauma 37:1933-1953.

Jha A, Lammertse DP, Coll JR, Charlifue S, Coughlin CT, Whiteneck GG, Worley G (2008) Apolipoprotein E epsilon4 allele and outcomes of traumatic spinal cord injury. J Spinal Cord Med 31:171176.

Kigerl KA, Gensel JC, Ankeny DP, Alexander JK, Donnelly DJ, Popovich PG (2009) Identification of two distinct macrophage subsets with divergent effects causing either neurotoxicity or regeneration in the injured mouse spinal cord. J Neurosci 29:1343513444.

Kitamura HW, Hamanaka H, Watanabe M, Wada K, Yamazaki C, Fujita SC, Manabe T, Nukina N (2004) Age-dependent enhancement of hippocampal long-term potentiation in knock-in mice expressing human apolipoprotein E4 instead of mouse apolipoprotein E. Neurosci Lett 369:173-178.

Klein RC, Mace BE, Moore SD, Sullivan PM (2010) Progressive loss of synaptic integrity in human apolipoprotein E4 targeted replacement mice and attenuation by apolipoprotein E2. Neuroscience 171:1265-1272.

Knouff C, Hinsdale ME, Mezdour H, Altenburg MK, Watanabe M, Quarfordt SH, Sullivan PM, Maeda N (1999) Apo E structure determines VLDL clearance and atherosclerosis risk in mice. J Clin Invest 103:1579-1586.

Korwek KM, Trotter JH, LaDu MJ, Sullivan PM, Weeber EJ (2009) ApoE isoform-dependent changes in hippocampal synaptic function. Mol Neurodegener 4:21.

Kulkarni P, Grant S, Morrison TR, Cai X, Iriah S, Kristal BS, Honeycutt J, Brenhouse H, Hartner JC, Madularu D, Ferris CF (2020) Characterizing the human APOE epsilon 4 knock-in transgene in female and male rats with multimodal magnetic resonance imaging. Brain Res 1747:147030.

Levi O, Jongen-Relo AL, Feldon J, Roses AD, Michaelson DM (2003) ApoE4 impairs hippocampal plasticity isoform-specifically and blocks the environmental stimulation of synaptogenesis and memory. Neurobiol Dis 13:273-282.

Lovett-Barr MR, Satriotomo I, Muir GD, Wilkerson JER, Hoffman MS, Vinit S, Mitchell GS (2012) Repetitive intermittent hypoxia induces respiratory and somatic motor recovery after chronic cervical spinal injury. J Neurosci 32:3591-3600.

Lynch M, Duffell L, Sandhu M, Srivatsan S, Deatsch K, Kessler A, Mitchell GS, Jayaraman A, Rymer WZ (2017) Effect of acute intermittent hypoxia on motor function in individuals with chronic spinal cord injury following ibuprofen pretreatment: a pilot study. J Spinal Cord Med 40:295-303.

Mahley RW (2016) Apolipoprotein E: from cardiovascular disease to neurodegenerative disorders. J Mol Med (Berl) 94:739-746.
Main BS, Villapol S, Sloley SS, Barton DJ, Parsadanian M, Agbaegbu C, Stefos K, McCann MS, Washington PM, Rodriguez OC, Burns MP (2018) Apolipoprotein E4 impairs spontaneous blood brain barrier repair following traumatic brain injury. Mol Neurodegener 13:17.

Massey JM, Amps J, Viapiano MS, Matthews RT, Wagoner MR, Whitaker CM, Alilain W, Yonkof AL, Khalyfa A, Cooper NGF, Silver J, Onifer SM (2008) Increased chondroitin sulfate proteoglycan expression in denervated brainstem targets following spinal cord injury creates a barrier to axonal regeneration overcome by chondroitinase ABC and neurotrophin-3. Exp Neurol 209:426445.

McGuire M, Zhang Y, White DP, Ling L (2005) Phrenic long-term facilitation requires NMDA receptors in the phrenic motonucleus in rats. J Physiol 567:599-611.

Minor KH, Akison LK, Goshgarian HG, Seeds NW (2006) Spinal cord injury-induced plasticity in the mouse-The crossed phrenic phenomenon. Exp Neurol 200:486-495.

National Spinal Cord Injury Statistical Center (2018) Spinal cord injury facts and figures at a glance. Birmingham, AL: University of Alabama at Birmingham. Available at https://www.nscisc.uab.edu/.

Navarrete-Opazo A, Mitchell GS (2014) Therapeutic potential of intermittent hypoxia: a matter of dose. Am J Physiol Regul Integr Comp Physiol 307:R1181-R1197.

Noble LJ, Wrathall JR (1989) Distribution and time course of protein extravasation in the rat spinal cord after contusive injury. Brain Res 482:57-66.

Pamenter ME, Powell FL (2016) Time domains of the hypoxic ventilatory response and their molecular basis. Compr Physiol 6:13451385.

Park KK, Liu K, Hu Y, Smith PD, Wang C, Cai B, Xu B, Connolly L, Kramvis I, Sahin M, He Z (2008) Promoting axon regeneration in the adult CNS by modulation of the PTEN/mTOR pathway. Science 322:963-966.

Pizzorusso T, Medini P, Berardi N, Chierzi S, Fawcett JW, Maffei L (2002) Reactivation of ocular dominance plasticity in the adult visual cortex. Science 298:1248-1251.

Raber J, Wong D, Buttini M, Orth M, Bellosta S, Pitas RE, Mahley RW, Mucke L (1998) Isoform-specific effects of human apolipoprotein $\mathrm{E}$ on brain function revealed in ApoE knockout mice: increased susceptibility of females. Proc Natl Acad Sci USA 95:1091410919.

Safieh M, Korczyn AD, Michaelson DM (2019) ApoE4: an emerging therapeutic target for Alzheimer's disease. BMC Med 17:64.

Satkunendrarajah K, Karadimas SK, Laliberte AM, Montandon G, Fehlings MG (2018) Cervical excitatory neurons sustain breathing after spinal cord injury. Nature 562:419-422.

Saunders AM, Strittmatter WJ, Schmechel D, St. George-Hyslop PH, Pericak-Vance MA, Joo SH, Rosi BL, Gusella JF, CrapperMacLachlan DR, Alberts MJ, Hulette C, Crain B, Goldgaber D, Roses AD (1993) Association of apolipoprotein E allele epsilon 4 with late-onset familial and sporadic Alzheimer's disease. Neurology 43:1467-1472.

Sen A, Nelson TJ, Alkon DL (2017) ApoE isoforms differentially regulates cleavage and secretion of BDNF. Mol Brain 10:19.

Sullivan PM, Mezdour H, Aratani Y, Knouff C, Najib J, Reddick RL, Quarfordt SH, Maeda N (1997) Targeted replacement of the mouse apolipoprotein E gene with the common human APOE3 allele enhances diet-induced hypercholesterolemia and atherosclerosis. J Biol Chem 272:17972-17980.

Sullivan PM, Mezdour H, Quarfordt SH, Maeda N (1998) Type III hyperlipoproteinemia and spontaneous atherosclerosis in mice resulting from gene replacement of mouse Apoe with human Apoe $^{\star 2}$. J Clin Invest 102:130-135.

Sullivan PG, Krishnamurthy S, Patel SP, Pandya JD, Rabchevsky AG (2007) Temporal characterization of mitochondrial bioenergetics after spinal cord injury. J Neurotrauma 24:991-999.

Sun C, Ji G, Liu Q, Yao M (2011) Apolipoprotein E epsilon 4 allele and outcomes of traumatic spinal cord injury in a Chinese Han population. Mol Biol Rep 38:4793-4796. 
Terada J, Nakamura A, Zhang W, Yanagisawa M, Kuriyama T, Fukuda Y, Kuwaki T (2008) Ventilatory long-term facilitation in mice can be observed during both sleep and wake periods and depends on orexin. J Appl Physiol (1985) 104:499-507.

Tester NJ, Fuller DD, Fromm JS, Spiess MR, Behrman AL, Mateika $\mathrm{JH}$ (2014) Long-term facilitation of ventilation in humans with chronic spinal cord injury. Am J Respir Crit Care Med 189:10091065.

Tom VJ, Kadakia R, Santi L, Houlé JD (2009) Administration of chondroitinase $A B C$ rostral or caudal to a spinal cord injury site promotes anatomical but not functional plasticity. J Neurotrauma 26:2323-2333.

Tran AP, Warren PM, Silver J (2018) The biology of regeneration failure and success after spinal cord injury. Physiol Rev 98:881-917.

Trommer BL, Shah C, Yun SH, Gamkrelidze G, Pasternak ES, Ye GL, Sotak M, Sullivan PM, Pasternak JF, LaDu MJ (2004) ApoE isoform affects LTP in human targeted replacement mice. Neuroreport 15:2655-2658.

Trumbower RD, Jayaraman A, Mitchell GS, Rymer WZ (2012) Exposure to acute intermittent hypoxia augments somatic motor function in humans with incomplete spinal cord injury. Neurorehabil Neural Repair 26:163-172.

Trumbower RD, Hayes HB, Mitchell GS, Wolf SL, Stahl VA (2017) Effects of acute intermittent hypoxia on hand use after spinal cord trauma: a preliminary study. Neurology 89:1904-1907.

Urban MW, Ghosh B, Block CG, Strojny LR, Charsar BA, Goulão M, Komaravolu SS, Smith GM, Wright MC, Li S, Lepore AC (2019) Long-distance axon regeneration promotes recovery of diaphragmatic respiratory function after spinal cord injury. eNeuro 6: ENEURO.0096-19.2019.
Wadhwa H, Gradinaru C, Gates GJ, Badr MS, Mateika JH (2008) Impact of intermittent hypoxia on long-term facilitation of minute ventilation and heart rate variability in men and women: do sex differences exist? J Appl Physiol (1985) 104:1625-1633.

Warren PM, Alilain WJ (2019) Plasticity induced recovery of breathing occurs at chronic stages after cervical contusion. J Neurotrauma 36:1985-1999.

Warren PM, Steiger SC, Dick TE, MacFarlane PM, Alilain WJ, Silver J (2018) Rapid and robust restoration of breathing long after spinal cord injury. Nat Commun 9:4843.

Zabka AG, Behan M, Mitchell GS (2001a) Long term facilitation of respiratory motor output decreases with age in male rats. J Physiol 531:509-514.

Zabka AG, Behan M, Mitchell GS (2001b) Selected contribution: time-dependent hypoxic respiratory responses in female rats are influenced by age and by the estrus cycle. J Appl Physiol (1985) 91:2831-2838.

Zabka AG, Mitchell GS, Olson EB, Behan M (2003) Selected contribution: chronic intermittent hypoxia enhances respiratory longterm facilitation in geriatric female rats. J Appl Physiol (1985) 95:2614-2623.

Zhao N, Liu CC, Qiao W, Bu G (2018) Apolipoprotein E, receptors and modulation of Alzheimer's disease. Biol Psychiatry 83:347357.

Zholudeva LV, Qiang L, Marchenko V, Dougherty KJ, SakiyamaElbert SE, Lane MA (2018) The neuroplastic and therapeutic potential of spinal interneurons in the injured spinal cord. Trends Neurosci 41:625-639.

Zhou W, Xu D, Peng X, Zhang Q, Jia J, Crutcher KA (2008) Metaanalysis of APOE4 allele and outcome after traumatic brain injury. J Neurotrauma 25:279-290. 